8-7-2009

\title{
Comment on "A Stochastic Biomechanical Model for Risk and Risk Factors of Non-Contact Anterior Cruciate Ligament Injuries"
}

Antonie J. van den Bogert

Cleveland State University, a.vandenbogert@csuohio.edu

Scott G. McLean

University of Michigan

Follow this and additional works at: https://engagedscholarship.csuohio.edu/enme_facpub

Part of the Biomechanical Engineering Commons

How does access to this work benefit you? Let us know!

\section{Publisher's Statement}

NOTICE: this is the author's version of a work that was accepted for publication in Journal of Biomechanics. Changes resulting from the publishing process, such as peer review, editing, corrections, structural formatting, and other quality control mechanisms may not be reflected in this document. Changes may have been made to this work since it was submitted for publication. A definitive version was subsequently published in Journal of Biomechanics, 42, 11, (08-07-2009); 10.1016/j.jbiomech.2009.03.055

\section{Original Citation}

van den Bogert, A. J., and McLean, S. G., 2009, "Comment on "A Stochastic Biomechanical Model for Risk and Risk Factors of Non-Contact Anterior Cruciate Ligament Injuries"," Journal of Biomechanics, 42(11) pp. 1778-1779.

This Response or Comment is brought to you for free and open access by the Mechanical Engineering Department at EngagedScholarship@CSU. It has been accepted for inclusion in Mechanical Engineering Faculty Publications by an authorized administrator of EngagedScholarship@CSU. For more information, please contact library.es@csuohio.edu. 
Letter to the Editor

\section{Comment on "A stochastic biomechanical model for risk and risk factors of non-contact anterior cruciate ligament injuries"}

Dear Editor,

We have read with great interest the recent article " $A$ stochastic biomechanical model for risk and risk factors of noncontact anterior cruciate ligament injuries" (Lin et al., 2009). Probabilistic models such as these are important because they have the potential to estimate subject-specific injury risk and suggest specific interventions for injury prevention.

Lin et al. (2009) found that, in females, sagittal plane mechanisms contributed $78 \%$ of the $\mathrm{ACL}$ load during those model simulations that caused injury (Table 7). This sagittal plane mechanism was attributed to large posterior ground reaction force at low knee flexion angles. In our own probabilistic simulations, however, we found the opposite result: sagittal plane load consistently remained at non-injurious levels and injuries were only caused by non-sagittal mechanisms (McLean et al., 2004). The discrepancy between the two studies was not discussed by Lin et al., and we feel that such a discussion is important to the readership of this journal because of its clinical implications for injury prevention.

The two studies looked at different sports movements (sidestep vs. stop-jump), but we do not believe these are essentially different, especially since both were stochastically modified to create a wider range of loading conditions. There are, however, important methodological aspects that must be discussed when comparing the two studies:

(1) Choice of time point. Lin et al. performed their analysis only at one time point in the stance phase: the time of maximum posterior ground reaction force. If the maximum non-sagittal loads occurred at a different time, their potential contribution would be underestimated. McLean et al. (2004) performed the analysis at every millisecond during the first $200 \mathrm{~ms}$ of the stance phase to eliminate this concern.

(2) Choice of probability distributions. Based on measurements in 40 subjects, a Gaussian distribution was used for the nonsagittal moments, and a Gamma distribution for the ground reaction forces. These distributions differ dramatically in their tail shape. A quick simulation based on Table 4 revealed that if a Gaussian distribution had been used for the posterior ground reaction force, there would have been a 15-fold reduction in the probability of a two body weight posterior ground reaction force, which is exactly where the simulated injuries occurred. This is a very large difference, entirely due

DOI of original article: 10.1016/j.jbiomech.2009.04.038 to the assumption that Gamma distribution from 40 subjects could be extrapolated to these high loading levels. There may not have been sufficient data in the tail of the distribution to justify this assumption.

(3) Lack of muscle physiology constraints. Lin et al., generated ground reaction forces and kinematic variables from a statistical model based on observed probability distributions. These distributions do not have an upper-limit to the loads that can be generated. McLean et al. generated knee joint loading with a forward dynamic model in which the initial conditions and muscle activations were stochastic input variables. This model was, therefore, unable to generate knee joint loading scenarios that are physiologically and mechanically impossible. With the purely statistical approach as used by Lin et al., however, such non-physiological events can occasionally occur and these may have dominated the results reported in the injury column in Table 7 . If we use the sagittal ACL load reported in Table 7 and the equations in the appendix to work backwards to estimate the knee extensor moment during the injury events, we find values between 264 and $411 \mathrm{Nm}$, well beyond the capacity of knee extensor muscles in females at $25^{\circ}$ flexion (Pincivero et al., 2004) and thus clearly non-physiological.

(4) Possible lack of dynamic consistency. It is not entirely clear how Lin et al. calculated the knee extensor moment from stochastically simulated ground reaction force and kinematics. Greenwood (1988) was cited in the Appendix but not listed in references, and could not be located in PubMed. During impact events such as these stop jumps, it is important to use inverse dynamic analysis which includes a term from posterior foot and shank acceleration. With optical motion capture, these accelerations are typically underestimated, causing knee extensor moment to be overestimated unless the ground reaction force is appropriately filtered (Bisseling and Hof, 2006). Furthermore, these accelerations are highly correlated to the posterior ground reaction force peak and when ground reaction forces are perturbed probabilistically, the accelerations should not be kept constant. Without proper methodology, knee extensor moment as well as patellar tendon force (and its contribution to $\mathrm{ACL}$ injury) could have been seriously overestimated. A clarification from the authors on their methods would be most welcome to eliminate this concern.

Lin et al. correctly predicted gender difference in injury risk that has been found epidemiologically. Tables 6 and 7 suggest that this is not because of a gender difference in joint loading during movement, but rather due to the gender difference in injury threshold for the ACL. Therefore, this prediction should not be interpreted as a validation of the load analysis that was performed. 
A correct load analysis is of utmost importance for clinical interpretation of these simulation studies. If sagittal mechanisms are important, as implied by Lin et al. (2009), athletes must be taught to reduce posterior ground reaction force, increase knee flexion, and reduce quadriceps force. If non-sagittal mechanisms are important, as implied by McLean et al., 2004, athletes must be taught to avoid knee valgus and internal/external rotation during sports movements. The latter strategy is consistent with prospective studies which have shown that athletes with high valgus loads have a higher risk of injury (Hewett et al., 2005). The sagittal loading hypotheses has not yet been confirmed by such prospective studies and is not well supported by the theoretical analysis of Lin et al. (2009), because of the methodological concerns we have pointed out above.

\section{References}

Bisseling, R.W., Hof, A.L., 2006. Handling of impact forces in inverse dynamics. Journal of Biomechanics 39, 2438-2444.

Hewett, T.E., Myer, G.D., Ford, K.R., Heidt Jr., R.S., Colosimo, A.J., McLean, S.G., van den Bogert, A.J., Paterno, M.V., Succop, P., 2005. Biomechanical measures of neuromuscular control and valgus loading of the knee predict anterior cruciate ligament injury risk in female athletes: a prospective study. American Journal of Sports Medicine 33, 492-501.

Lin, C.F., Gross, M., Ji, C., Padua, D., Weinhold, P., Garrett, W.E., Yu, B., 2009. A stochastic biomechanical model for risk and risk factors of non-contact anterior cruciate ligament injuries. Journal of Biomechanics 42, 418-423.

McLean, S.G., Huang, X., Su, A., van den Bogert, A.J., 2004. Sagittal plane biomechanics cannot injure the ACL during sidestep cutting. Clinical Biomechanics 19, 828-838.

Pincivero, D.M., Salfetnikov, Y., Campy, R.M., Coelho, A.J., 2004. Angle- and genderspecific quadriceps femoris muscle recruitment and knee extensor torque. Journal of Biomechanics 37, 1689-1697.

Antonie J. van den Bogert* Department of Biomedical Engineering, Cleveland Clinic, Cleveland,

OH, USA

E-mail address: bogerta@ccf.org

Scott G. McLean

School of Kinesiology, University of Michigan, Ann Arbor, MI, USA

E-mail address: mcleansc@umich.edu

11 March 2009; accepted 12 March 2009 